\title{
O estudo da Óptica na modalidade de Educação para Jovens e Adultos (EJA) por meio de uma sequência didática diversificada ${ }^{+}$
}

\author{
Elisete Lopes da Cunha ${ }^{1}$ \\ Centro Universitário UNA \\ Adriana Gomes Dickman ${ }^{2}$ \\ PUC-MINAS \\ Belo Horizonte - MG
}

\section{Resumo}

Neste artigo discutimos a aplicação de uma sequência didática para ensinar Óptica para alunos da Educação de Jovens e Adultos (EJA). A sequência de atividades, composta por estratégias como exibição de vídeos, leitura de artigos de divulgação científica, reconstrução e demonstração de experimentos, e discussões em grupo, foi elaborada tendo por base um ensino de física contextualizado visando uma formação caracterizada pela autonomia intelectual e pensamento crítico. O referencial teórico baseia-se na abordagem histórico-cultural de Vygotsky, que inter-relaciona o aprendizado e o desenvolvimento do indivíduo com a interação deste com o meio social. Na aplicação da sequência de atividades, duas etapas foram essenciais: o pré-teste, no qual foram identificadas as necessidades de aprendizagem dos alunos, bem como seus conhecimentos prévios sobre fenômenos da Óptica; e o pós-teste, que permitiu identificar o desenvolvimento da aprendizagem na maioria dos alunos, indicando o início de uma construção de conceitos científicos a partir dos conceitos espontâneos previamente identificados.

Palavras-chave: Educação de jovens e adultos; Vygotsky; Óptica.

\footnotetext{
${ }^{+}$Studying optics with young people and adults through a diversified didactic sequence

* Recebido: julho de 2017. Aceito: dezembro de 2017.

${ }^{1}$ E-mail: elisete.cunha@prof.una.br; ${ }^{2}$ E-mail: adrianadickman@gmail.com
} 


\begin{abstract}
In this paper, we discuss the application process of a didactic sequence for teaching young people and adults about Optics at high school level. The sequence incorporates teaching strategies such as video exhibition, reading and discussion of science popularization papers, demonstrations and reconstruction of experiments. The activities take into account the contextualization of physics concepts to everyday phenomena, developing the student's intellectual autonomy and critical reasoning. In this sense, we use the sociohistorical theory of Vygotsky as a reference, as it associates the apprenticeship and the individual's development with his social interaction. Two activities of the sequence we consider essential are: the pre-test questionnaire, identifying the students' needs, as well as their spontaneous concepts about optics; and the post-test questionnaire, which made it possible to identify a tendency of learning in most of the students, indicating an initial process of scientific concepts construction from spontaneous ones.
\end{abstract}

Keywords: Education of Young People and Adults; Vygotsky, Optics.

\title{
I. Introdução
}

Educação de qualidade para todos constitui-se em um fator indispensável para a inserção na atual sociedade, caracterizada por mudanças constantes e inovações em todos os setores. A necessidade de formação dos cidadãos é justificada por três fatores: a revolução tecnológica, as inovações produtivas e a evolução acelerada na área da informação e comunicação. Por se tratar de sociedade é preciso destacar a importância da educação na formação da cidadania. As pessoas percebem a educação como uma maneira de se inserir na sociedade do conhecimento principalmente, porque esta pode proporcionar uma formação sociocultural que permite ao cidadão fazer parte de um processo evolutivo, propiciando novas escolhas e oportunidades. O ser humano, além de fazer parte da sociedade, quer também adquirir uma formação em Ciências, favorecendo uma participação crítica, que lhe permita fazer inferências e intervenções contribuindo para transformar a realidade.

A educação pode possibilitar ao indivíduo retomar seu potencial, desenvolver habilidades, reconhecer capacidades desenvolvidas em seu cotidiano. Desta maneira, esses cidadãos poderão questionar e compreender fenômenos inerentes ao mundo, e até mesmo contribuir com novas ideias. Como caso particular, problematiza-se a educação de jovens e $\operatorname{adultos}^{2}$ nessa busca pelo conhecimento.

\footnotetext{
2 Modalidade de ensino destinada àqueles que não tiveram acesso ou continuidade de estudos no ensino fundamental e médio na idade própria. (BRASIL, 1996).
} 
Pela necessidade em mudar, na qual o valor social dado à escola é essencial, muitos jovens e adultos retornam à escola com o objetivo de investimento na continuidade de sua formação básica. Esta decisão pode ser explicada pela tentativa deles de acompanhar as inúmeras mudanças promovidas pela evolução da ciência e da tecnologia que impacta diretamente o seu cotidiano. De acordo com Pietrocola (2005, p. 15), o fato do cotidiano ser permeado por artefatos tecnológicos, exige uma formação distinta do cidadão, que sente a necessidade de uma alfabetização científico-tecnológica. Assim, essas pessoas buscam por meio da escola uma oportunidade de se integrarem a esse mundo inovador. A decisão em retomar os estudos requer disposição, comprometimento e o real desejo de aprender. Desta forma, na busca por melhores oportunidades de trabalho e de vida, jovens e adultos demonstram compromisso e dedicação para alcançar uma formação sólida. É neste momento, em nossa opinião, que os educadores, envolvidos com esta modalidade de ensino, devem assumir a tarefa de estabelecer uma conexão entre o conhecimento e a realidade dessas pessoas.

Reflete-se a importância da mudança na prática educativa dos educadores, que devem se apropriar criticamente de uma proposta de ensino específica ${ }^{3}$ para a Educação de jovens e adultos (EJA), que orienta a formação de todos os cidadãos como elemento crucial de desenvolvimento social (BRASIL, 2002). Essa proposta de ensino, formada a partir das orientações dos Parâmetros Curriculares Nacionais (PCN), busca "dar significado ao conhecimento escolar, mediante a contextualização; evitar a compartimentalização, mediante a interdisciplinaridade; e incentivar o raciocínio e a capacidade de aprender" (BRASIL, 2000, p.4).

Para implementar uma proposta de ensino, que tem como principal objetivo melhorar o processo de aprendizagem dos alunos, cabe primeiramente ao professor conscientizar-se da necessidade de ações práticas, como por exemplo, a tentativa de buscar novas estratégias de ensino. Dentro desta proposta encontra-se o Exame Nacional para Certificação de Jovens e Adultos (ENCCEJA), que

[...] procura avaliar para certificar competências que expressam um saber constituinte, ou seja, as possibilidades e habilidades cognitivas por meio das quais as pessoas conseguem se expressar simbolicamente, compreender fenômenos, enfrentar e resolver problemas, argumentar e elaborar propostas em favor de sua luta por uma sobrevivência mais justa e digna (BRASIL, 2002, p. 28).

Neste contexto ressalta-se a importância da utilização de estratégias de ensino que vão além do quadro-e-giz, as quais podem dar suporte ao professor para que o mesmo consiga

\footnotetext{
3 Uma proposta de ensino que valorize a autonomia do estudante em ler informações e estabelecer relações a partir de certos contextos e situações; que sinaliza e valoriza um cidadão mais apto a viver em um mundo em constantes transformações, onde é importante possuir estratégias pessoais e coletivas para a solução de problemas, fundamentadas em conhecimentos básicos de todas as disciplinas ou áreas da educação básica. (BRASIL, 2002, p. 14)
} 
desenvolver em seus alunos as habilidades e competências da área de Ciências da Natureza e suas Tecnologias, propostas pelo ENCCEJA ${ }^{4}$ :

I. Compreender as ciências como construções humanas, relacionando o desenvolvimento científico ao longo da história com a transformação da sociedade; II. Compreender o papel das ciências naturais e das tecnologias a elas associadas, nos processos de produção e no desenvolvimento econômico e social contemporâneo; III. Identificar a presença e aplicar as tecnologias associadas às ciências naturais em diferentes contextos relevantes para sua vida pessoal; VII. Apropriar-se de conhecimentos da física para compreender o mundo natural e para interpretar, avaliar e planejar intervenções científico-tecnológicas no mundo contemporâneo (BRASIL, 2006, p. 8).

Uma breve investigação sobre a produção acadêmica feita evidencia que poucos trabalhos discutem o Ensino de Física voltado para a EJA, apontando sugestões para melhoria nesta modalidade de ensino, tendo em vista que os conteúdos devem ser tratados de maneira diferenciada, buscando considerar o conhecimento prévio do aluno no processo de ensino e aprendizagem. Embora os trabalhos encontrados apresentem diferentes enfoques e metodologias, todos têm um objetivo em comum, ou seja, melhorar a qualidade do Ensino de física na EJA, por meio de um ensino contextualizado buscando uma formação geral para os alunos. Como exemplo destes trabalhos tem-se: uma discussão sobre maneiras alternativas para ensinar conceitos de eletricidade em que o autor faz a releitura e aplicação de textos publicados pelo ENCCEJA, utilizando o livro do Grupo de Reelaboração do Ensino de Física - GREF (GREF, 1993) e uma cartilha com dicas de segurança, publicada por uma companhia de energia elétrica (COSTA, 2008); discussão sobre conceitos relacionados à radiação, envolvendo a leitura de artigos de revistas de divulgação científica, textos complementares, entrevistas e outras estratégias (FERREIRA, 2005); discussão de conceitos de mecânica por meio da discussão de textos complementares e visitas de campo (KRUMMENAUER; COSTA; SILVEIRA, 2007). Outros trabalhos (ESPÍNDOLA, 2006; BRESOLIN, 2014) priorizam metodologias que discutem a física de maneira contextualizada e descrevem uma abordagem para a EJA baseada em projetos temáticos; e Mello et al. (2011) que sugerem a construção de experimentos simples, utilizando materiais alternativos, além da elaboração de kits e manuais de laboratório.

Com base nos trabalhos investigados e na experiência pessoal de uma das autoras como aluna e professora da EJA, percebe-se que essas turmas são caracterizadas por alunos com uma faixa etária bastante diversificada, que reflete na heterogeneidade de objetivos de retorno ao estudo; dificuldades em conceitos, como operações básicas de matemática, em geral em função do período que ficaram longe da escola; desejo de aprender e valorização do professor, o que estimula o trabalho docente; em particular, em vários momentos, foi percebi-

\footnotetext{
${ }^{4}$ São citadas as competências e habilidades relacionadas à Física.
} 
da uma falta de espaço ou liberdade para questionamentos sobre o conteúdo discutido, que pode acarretar na frustração deste aluno que traz uma rica bagagem baseada na sua experiência de vida.

Assim, considerando as orientações oficiais destacadas anteriormente sobre a importância da modalidade de Ensino de Jovens e Adultos (eg. LDB, PCN, ENCCEJA), as características dos alunos da EJA e discussões acadêmicas, elaborou-se uma proposta composta por uma sequência de atividades para o ensino de Óptica, como material de apoio para professores da modalidade EJA.

Neste contexto da pesquisa, busca-se responder à questão: A partir de uma intervenção, considerando uma sequência didática centrada em uma diversidade de técnicas de ensino (eg. Uso de tecnologias, experimentos, leituras de textos científicos, argumentação), é possível provocar o desenvolvimento da aprendizagem, sobre tópicos da óptica, em alunos da EJA de uma escola privada? Para apoiar a realização deste estudo utilizou-se o referencial teórico proposto por Levy Vygotsky como será apresentado no tópico a seguir.

\section{Vygotsky e a sequência de atividades}

A abordagem histórico-cultural da teoria de Vygotsky pode auxiliar, em nossa opinião, a elaboração de uma proposta de ensino nos moldes sugeridos pelos PCN. Este documento sugere que a educação em ciências ofereça ao aluno uma formação que lhe permita compreender o mundo em que vive, estabelecendo relações entre o cotidiano e o conhecimento científico, para que o educando seja capaz de fazer inferências sobre situações de sua vivência para o desenvolvimento de capacidades mentais, como autonomia intelectual, criatividade, solução de problemas, análise, entre outras (BRASIL, 2000).

Desta maneira, o processo de elaboração da sequência didática teve como aporte teórico a teoria de Vygotsky, que inter-relaciona o aprendizado e o desenvolvimento do indivíduo com a interação deste com o meio social no qual está inserido. Além disso, essa teoria orientou as discussões sobre a importância dos conceitos espontâneos, a formação de conceitos científicos, e o papel do professor como mediador.

Vygotsky enfatiza em sua obra a importância dos processos de aprendizado, uma vez que a relação entre o aprendizado e a formação sociocultural do indivíduo é uma consequência da relação direta entre o desenvolvimento humano e o aprendizado. Para Vygotsky (1984, p. 61), desde o nascimento, o aprendizado da criança está relacionado ao desenvolvimento e é "um aspecto necessário e universal do processo de desenvolvimento das funções psicológicas culturalmente organizadas e especificamente humanas".

Neste contexto, priorizou-se o desenvolvimento de um trabalho que possa despertar no aluno processos internos relacionados com sua formação científica, tecnológica e social. Resgatando, assim, uma educação que conecte o cotidiano dessas pessoas com a sua vida escolar, promovendo o desenvolvimento sociocultural dos alunos, e a formação de um cidadão 
com pensamento crítico, que saiba se relacionar com o ambiente em que vive (OLIVEIRA, 1997).

Nesta concepção, o aprendizado se torna um fator de extrema importância para um bom convívio social. "O ser humano cresce num ambiente social e a interação social com outras pessoas é essencial ao seu desenvolvimento" (OLIVEIRA, 1997, p. 57). Estabelecendo uma relação com o aprendizado escolar, mais especificamente da EJA, percebe-se que o convívio social se destaca como um fator de grande importância na formação dos alunos. Ao adquirir um bom aprendizado, os alunos adquirem autoestima, demonstram convicção dos conhecimentos adquiridos, e evoluem na maneira de se comunicarem, tornando-se assim, aptos para um bom convívio social.

Na concepção vygotskyana, o aprendizado ocorre através de níveis de desenvolvimento, indicados como nível de desenvolvimento real $^{5}$ e nível de desenvolvimento proximal. ${ }^{6}$ A característica que os distingue é a capacidade de um indivíduo realizar determinadas tarefas. Vygotskii (2010) ressalva que não se deve medir o nível de desenvolvimento intelectual de uma criança pela quantidade de tarefas executadas por ela independentemente, mas sim pelas tarefas que a mesma é capaz de executar com o auxílio de um adulto. Assim, para uma situação em que um indivíduo precisa realizar uma atividade inovadora, a qual exija do mesmo o conhecimento de algo que ainda não foi ensinado, ele deverá contar com o auxílio do professor, para que consiga realizar com êxito tal atividade, passando a um nível mais elevado de desenvolvimento intelectual. Nessa perspectiva, para compreender de fato o aprendizado de um indivíduo deve-se considerar não apenas o nível de desenvolvimento real, mas também o seu nível de desenvolvimento potencial. A distinção entre tarefas realizadas de forma independente e aquelas realizadas sob a orientação de outra pessoa acontece através de uma região denominada zona de desenvolvimento proximal $^{7}$ (VYGOTSKY, 1984).

A teoria de Vygotsky estabelece que o ensino formal, o qual se adquire em um ambiente escolar, é um fator essencial que contribui de forma consistente para o processo de aprendizagem das crianças, e consequentemente para o desenvolvimento intelectual das mesmas. Para Vygotskii (2010), ao destacar a importância entre o desenvolvimento intelectual e a zona de desenvolvimento proximal, o professor deverá ser um mediador entre os alunos e o conhecimento, estabelecendo uma relação entre os conceitos ensinados na escola e os conceitos construídos pela sociedade.

Vygotsky (2001) distingue o conhecimento espontâneo do conhecimento científico em termos de suas características e maneiras de aquisição. Os conceitos científicos são definidos por sua generalidade e organização sistematizada, características que não são encontradas

\footnotetext{
5 “Capacidade de realizar tarefas já aprendidas” independentemente. (VYGOTSKII, 2010, p. 111).

6 Também conhecido como nível de desenvolvimento potencial, refere-se ao que uma criança é capaz de fazer com o auxílio dos adultos. (VYGOTSKII, 2010, p. 112).

7 “A expressão zona de desenvolvimento proximal define as funções que ainda não amadureceram, mas que estão em processo de maturação”. (VYGOTSKY, 1984, p. 97).
} 
nos conceitos espontâneos, intimamente ligados às experiências do dia a dia, cuja aquisição se baseia no contato da criança com o meio social, construído através de experiências do cotidiano. Segundo Vygotsky (2001), a construção de conceitos científicos ocorre através de atividades bem planejadas e estruturadas em um ambiente educacional. Essas atividades devem ser aplicadas com o auxílio do professor, para a formação conceitual dos alunos, por meio de abstrações mais formais e conceitos melhor definidos do que os adquiridos de forma espontânea. Entretanto, Vygotsky ressalta a importância da unicidade cognitiva na aquisição desses conceitos, pois

o desenvolvimento dos conceitos espontâneos e científicos - cabe pressupor - são processos intimamente interligados, que exercem influências um sobre o outro. [...] independentemente de falarmos do desenvolvimento dos conceitos espontâneos ou científicos, trata-se do desenvolvimento de um processo único de formação de conceitos, que se realiza sob diferentes condições internas e externas, mas continua indiviso por sua natureza e não se constitui da luta, do conflito e do antagonismo de duas formas de pensamento que desde o início se excluem (VYGOTSKY, 2001, p. 261).

Entende-se que a concepção vygotskyana trabalha sempre com a ideia de que o indivíduo reconstrói, reelaborando os significados transmitidos pelo grupo cultural. E concorda-se com Oliveira quando afirma que:

O único bom ensino, afirma Vygotsky é aquele que se adianta ao desenvolvimento. Os procedimentos regulares que ocorrem na escola, demonstração, assistência, fornecimento de pistas, instruções, são fundamentais na promoção do bom ensino (OLIVEIRA, 1997, p. 62).

Neste sentido, acredita-se que a escola exerce um papel muito importante na formação de conceitos científicos pelo estudante, por meio dela o professor pode proporcionar ao aluno situações que requerem o desenvolvimento destes conceitos para explicá-las.

No processo de ensino e aprendizagem, a atividade escolar em grupo é essencial, pois abre espaço para que a intervenção não seja feita somente pelo professor e sim pelos demais alunos. Estabelecer tarefas que exijam que os alunos trabalhem os limites de sua zona de desenvolvimento proximal é fundamental, pois "o que a criança é capaz de fazer hoje em colaboração conseguirá fazer amanhã sozinha” (VYGOTSKY, 2001, p. 331). Desta forma, entende-se o quanto as ideias de Vygotsky valorizam a troca de experiência no ambiente escolar.

Nesta perspectiva, elaborou-se uma sequência didática que consiste na utilização de várias estratégias para o ensino de Óptica, com utilização de experimentos e demonstrações, exibição de vídeos e leitura de artigos. Embasado na teoria de Vygotsky, foi dada ênfase especial na questão da formação de conceitos, além da escolha de situações que permitem a aplicação dos conhecimentos prévios dos alunos, etapas importantes no processo de aprendizagem. Priorizou-se também o papel fundamental da mediação, na interação professor/aluno e 
no esforço de apresentação e aquisição dos conhecimentos científicos por meio de atividades planejadas e estruturadas para desenvolver habilidades que favoreçam ao aprendizado, com a realização de trabalhos em grupo, discussões e debates. Por último, vale ressaltar que as atividades foram escolhidas de modo a tirar vantagem da heterogeneidade da turma EJA, propiciando momentos em que alunos com um nível de desenvolvimento maior pudessem auxiliar os outros na realização das tarefas.

\section{Desenvolvimento e realização da proposta}

Para desenvolver este trabalho, foi escolhida a modalidade EJA de uma escola particular de Belo Horizonte (MG). A sequência de atividades foi aplicada em uma turma do segundo ano do Ensino médio, formada por 20 alunos, com uma faixa etária variando entre 16 e 40 anos.

A aplicação da sequência didática foi realizada por uma das autoras deste trabalho, que lecionava a disciplina Física para três turmas do segundo ano e apenas uma do primeiro ano. Dessa maneira, a necessidade de um tempo para preparar as atividades antes de aplicálas, definiu o conteúdo de Óptica, que é discutido na segunda etapa do segundo semestre. Assim, as atividades foram aplicadas de agosto a outubro de 2009 , tendo uma duração de dez aulas de 50 minutos.

As estratégias aplicadas foram divididas da seguinte maneira: (E1) Elaboração e aplicação de um questionário pré-teste; (E2) Exibição de teleaulas e discussão das questões do pré-teste; (E3) Leitura de artigos de divulgação científica e textos; (E4) Debate entre os alunos, sobre os textos e artigos; (E5) Reconstrução de experimentos; (E6) Apresentação dos experimentos para a turma; (E7) Aplicação e análise do questionário pós-teste. A seguir detalha-se a aplicação de cada estratégia, justificando a escolha das atividades. Mais detalhes sobre a construção da sequência podem ser encontrados em (CUNHA; DICKMAN; 2012; CUNHA, 2011).

Para análise dos dados coletados no pré- e pós-teste optou-se em utilizar a abordagem proposta pela Análise Textual Discursiva de Moraes e Galiazzi (2007), desta maneira, pode-se ter acesso aos detalhes das respostas do questionário. Estes autores indicam a unitarização, que consiste em "examinar os textos em seus detalhes, fragmentando-os no sentido de atingir unidades constituintes, enunciados referentes aos fenômenos estudados" (MORAES; GALIAZZI, p.11). Para os autores a junção dos pequenos detalhes constitui um todo que será responsável pela compreensão de cada resposta.

$\mathrm{Na}$ análise das respostas dos alunos ao questionário aplicado foram consideradas unidades de significação, buscando identificar um padrão que caracterize as ideias prévias sobre o tema abordado. Todos os 20 alunos da turma participaram de todas as estratégias, assim, utilizou-se o sistema alfanumérico para identificá-los, $\mathrm{A}_{1}, \mathrm{~A}_{2}, \mathrm{~A}_{3} \ldots \mathrm{A}_{20}$, resguardando-se a identidade dos mesmos. 


\section{A. Aplicação da estratégia E1}

A primeira estratégia utilizada foi o pré-teste, mostrado na tabela 1, que foi elaborado considerando seis questões abertas que investigavam conhecimentos dos estudantes sobre conceitos básicos de Óptica (eg. questões 1, 2 e 6) e algumas aplicações relacionadas a fenômenos físicos, presentes em nosso cotidiano (eg. questões 3, 4 e 5).

Tabela 1 - Questionário utilizado como pré-teste.

Q1. O que é luz?
Q2. O que são ondas eletromagnéticas?
Q3. Como enxergamos os objetos que não emitem luz?
Q4. Porque nos vemos num espelho?
Q5. Como é formado o arco-íris?
Q6. Cite as propriedades da luz que você conhece. Explique-as.

Fonte: Dados da pesquisa.

O questionário pretendeu explorar se os alunos eram capazes de estabelecer relação entre a física escolar e os conhecimentos do cotidiano sobre a Óptica. Assim, o objetivo do questionário foi saber se o aluno possuía uma visão crítica sobre os fenômenos físicos que fazem parte de seu cotidiano. A atividade teve a duração de uma aula de 50 minutos.

Ao analisar as respostas dos alunos à primeira questão, sobre o que é luz, foram definidas três categorias: Não sei, Associações isoladas e Associações pertinentes. Na categoria Não sei, nove alunos responderam que não sabem dizer o que é luz. Em Associações isoladas, quatro alunos associaram luz com brilho ou claridade, onda mecânica, força eletromagnética, como na resposta do aluno $\mathrm{A}_{2}$ :

Aluno $\mathrm{A}_{2}$ : “É o brilho refletido de cada objeto, ou pessoa, ou seja, é o brilho da matéria”.

Estas associações podem ser consideradas como concepções espontâneas, adquiridas por uma percepção sensorial ou concepções científicas malformadas, ao definir luz como uma onda mecânica ou força eletromagnética.

Na categoria Associações pertinentes, com um total de sete respostas, quatro alunos relacionaram luz com energia, como pode ser visto nos exemplos:

Aluno $\mathrm{A}_{17}$ : "É um feixe de energia";

Aluno $\mathrm{A}_{12}$ : "Luz é energia";

Aluno $\mathrm{A}_{7}$ : "É uma energia que vem de acordo com as ondas eletromagnéticas";

e três alunos usaram em suas respostas a palavra cores, associando-a a existência da luz, indicando talvez uma relação com seu espectro ou com um raio de luz, como em: 
Aluno $\mathrm{A}_{10}$ : "É um conjunto de cores emitidas pelo Sol".

Embora as respostas desta categoria contenham palavras que caracterizam o fenômeno da luz, nenhum aluno respondeu completamente a esta questão, ou seja, indicando que

A Luz é um fenômeno eletromagnético que transporta energia e se origina dos movimentos acelerados dos elétrons constituindo apenas uma minúscula parte de um todo maior, a larga faixa das ondas eletromagnéticas chamadas espectros eletromagnéticos (HEWITT, 2002, p. 440).

A resposta do aluno $A_{7}$ foi considerada a que mais se aproximou da resposta esperada, ao mencionar a energia das ondas eletromagnéticas.

$\mathrm{Na}$ análise da segunda questão, "O que são ondas eletromagnéticas”, não foi possível encontrar nenhuma resposta completa, indicando que as ondas eletromagnéticas são: "A ocorrência de uma perturbação eletromagnética constituída por campos elétricos e magnéticos variando com o tempo e que pode se propagar de uma região do espaço para outra, mesmo quando não existe nenhuma matéria entre essas regiões" (HEWITT, 2002). Assim, metade da turma (dez alunos) declarou não ser capaz de responder. As respostas de quatro alunos foram associadas à palavra Energia,

Aluno $\mathrm{A}_{7}$ : "São energias que passam em todos os lugares da cidade”;

Aluno $\mathrm{A}_{13}$ : "É um tipo de energia".

As respostas de quatro alunos foram classificadas por Magnetismo, em que os alunos utilizaram fenômenos magnéticos para explicar onda eletromagnética, como nas respostas:

Aluno $\mathrm{A}_{18}$ : "São ondas elétricas que percorrem lugares que possuem magnetismo";

Aluno $\mathrm{A}_{3}$ : "São ondas que emitem atração a um objeto, como por exemplo: o ímãa".

As respostas de dois alunos definiram a categoria Termos similares, por representarem palavras que possuem o mesmo prefixo, mas significados distintos, exemplificada por:

Aluno $\mathrm{A}_{15}$ : "Ondas que possuem magnésio".

A partir desta análise constata-se que os alunos desconheciam conceitos básicos sobre ondas eletromagnéticas, principalmente, porque não foram percebidas respostas associadas à origem destas ondas, ou uma referência à sua capacidade de propagar no vácuo. Por outro lado, observa-se que alguns alunos entendem que as ondas eletromagnéticas estão presentes no dia a dia; em outros casos percebe-se que os mesmos aproveitaram as palavras utilizadas no enunciado da pergunta para compor suas respostas.

A análise da terceira questão mostrou que as várias razões dadas pelos alunos para enxergar objetos que não emitem luz própria distancia-se da explicação conceitual proposta pela física escolar. Classificaram-se as respostas dos alunos de acordo com as seguintes cate- 
gorias: Não sei; Tamanho dos objetos; Propriedades da luz; Câmara escura; Outras respostas. Assim, seis alunos afirmaram que não sabem responder à questão, definindo a categoria Não sei. Na categoria Tamanho dos objetos, quatro alunos relacionaram o fato de ser possível enxergar um objeto com o seu tamanho, como nos exemplos a seguir:

Aluno $\mathrm{A}_{3}$ : "Porque eles têm um tamanho, uma porção de matéria visível a olho nu"; Aluno $\mathrm{A}_{15}$ : "Porque eles não refletem um tamanho mais fácil a nossa visão",

ou seja, na concepção desses alunos, pode-se enxergar em quaisquer condições um objeto grande que não emita luz. Dois alunos explicaram este fato por meio da reflexão das cores por estes objetos, como nas respostas abaixo que foram classificadas como Propriedades da luz:

Aluno $\mathrm{A}_{14}$ : "Porque vemos o que reflete nesses objetos, o reflexo das cores";

Aluno $\mathrm{A}_{10}$ : "Pois eles absorvem certas cores e refletem as outras para os nossos olhos".

Na categoria Câmara escura, três alunos associaram o funcionamento dos olhos ao de uma câmara escura:

Alunos $\mathrm{A}_{12} / \mathrm{A}_{13} / \mathrm{A}_{17}$ : "Porque nossos olhos funcionam como uma câmara escura";

sem especificar o que ocorre durante a captação da imagem. As respostas de cinco alunos foram classificadas como Outras respostas por citarem ideias diversas como iluminação do ambiente, Sol, objetos ofuscos e propriedades dos nossos olhos, como nas respostas:

Aluno A9: "Porque são objetos ofuscos";

Aluno $\mathrm{A}_{19}$ : "Porque são objetos que emitem a luz do Sol";

Aluno $\mathrm{A}_{11}$ : "Um objeto não precisa emitir luz para enxergarmos, basta estar em um ambiente iluminado".

A resposta do Aluno $\mathrm{A}_{11}$, embora reflita um fato verdadeiro, é bastante simplificada, pois não explica o processo solicitado pela questão. Assim, de acordo com Hewitt (2002, p.467),

A maior parte das coisas que vemos ao nosso redor não emite luz própria. Entretanto, elas são visíveis porque refletem a luz que incide em suas superfícies, vinda de uma fonte primária tal como o Sol ou uma lâmpada, ou de uma fonte secundária tal como o Céu iluminado.

Assim, as respostas dos alunos $\mathrm{A}_{10}$ e $\mathrm{A}_{14}$ foram as que mais se aproximaram do esperado.

As respostas dadas pelos alunos a quarta questão, que buscou investigar suas concepções sobre por que é possível enxergar imagens em um espelho plano, leva a construção de apenas duas categorias: Propriedades (onze alunos) e Não sei (nove alunos). 
Dentro da categoria Propriedades, foram enquadradas as respostas de três alunos contendo a palavra refletora, ou seja, para os alunos o espelho funciona como um aparelho refletor, como ilustrado na resposta:

Aluno $\mathrm{A}_{18}$ : "Porque ele é um refletor de imagem".

Enquanto que a palavra reflete apareceu nas respostas de oito alunos, sendo todas relacionadas com o fenômeno de reflexão, como em

Aluno $\mathrm{A}_{5}$ : "Porque ele reflete";

Aluno $\mathrm{A}_{1}$ : "Porque o espelho reflete a mesma luz do ambiente".

Entretanto, deve-se destacar que algumas respostas, mesmo apresentando essa relação, estavam em desacordo com a explicação da física escolar. Neste contexto, tem-se a resposta:

Aluno $\mathrm{A}_{15}$ : "Porque todo espelho tem um fundo negro atrás dele, sendo assim as cores batem e não refletem formando nossa imagem".

Percebe-se que o aluno sabia detalhes da construção de um espelho, provavelmente adquiridos no cotidiano, mas desconhecia o processo de formação de imagens. Este aluno utiliza a palavra cores para se referir ao raio de luz.

Ao explicar como é formado o arco-íris, na quinta questão, várias respostas relacionaram o fenômeno ou com a refração ou com a reflexão, separadamente, e observa-se que a maioria dos alunos não conseguiu responder completamente à pergunta, de acordo com a explicação:

Um raio de luz ao atingir a superfície da gotícula terá parte da luz refletida e parte refratada. Na parte refratada, a luz é dispersa nas cores de seu espectro, o violeta sendo a mais desviada e o vermelho a menos desviada das cores, cada uma das cores é parcialmente refratada para o ar exterior e parcialmente refletida de volta para a água (HEWITT, 2002, p. 479).

As respostas foram classificadas em três categorias: Não sei (10 alunos), Propriedades da luz (8 alunos) e Outras respostas (2 alunos). Dentro da categoria Propriedades da luz foram enquadradas respostas que mencionam a Reflexão como nas respostas dos estudantes abaixo:

Aluno $\mathrm{A}_{1}$ : "Isso ocorre quando o reflexo do Sol bate nas moléculas pequenas de água e mostram todas as cores que a cor branca tem";

Aluno $\mathrm{A}_{2}$ : "É o reflexo do branco em todas as gotículas de umidade do ar".

E as respostas que mencionam a palavra Cores como em:

Aluno $\mathrm{A}_{15}$ : "São as cores que batem na Luz do sol e se refletem". 
Aluno $\mathrm{A}_{5}$ : "O arco-íris é formado pelo encontro de todas as cores".

Em Outras respostas observam-se associações às palavras: força, Sol e ou chuva, como nos exemplos fornecidos abaixo:

Aluno $\mathrm{A}_{13}$ : "Pela força do Sol";

Aluno $\mathrm{A}_{10}$ : "Depois que chove e o Sol raia, forma o arco-íris".

A resposta do aluno $\mathrm{A}_{1}$ foi considerada a mais completa. Metade dos alunos declarou que não sabia descrever como ocorre o arco-íris. Esse último dado chamou a atenção, pois apesar de todos os alunos terem afirmado que já haviam presenciado este fenômeno físico, nenhum deles buscou uma explicação científica sobre a sua formação.

Na sexta questão, ao citar ou explicar as propriedades da luz, esperava-se que os alunos mencionassem propriedades relacionadas à velocidade, reflexão ou refração da luz, propagação retilínea, reversibilidade ou independência dos raios luminosos dentro do limite da Óptica geométrica. Essa foi a questão que apresentou o maior número de respostas (15 alunos) do tipo Não sei, definindo esta categoria. O restante dos alunos citou alguma propriedade, sem explicá-las. Assim, classificaram-se as respostas de acordo com as propriedades citadas: Reflexão, em que dois alunos responderam:

Aluno $\mathrm{A}_{20}$ : "É uma fonte de reflexão";

Aluno $A_{10}$ : "Reflexão";

Velocidade, como na resposta de um aluno:

Aluno $A_{18}$ : "Não há velocidade maior que a da luz";

Composição da luz branca, explicada por um aluno na resposta:

Aluno $A_{1}$ : "É composta por cores primárias que quando se juntam se transformam na cor branca".

E finalmente, Energia/Onda, em que um aluno apenas cita:

Aluno $A_{8}$ : "Energia, ondas eletromagnéticas".

Uma análise geral das respostas ao pré-teste mostra que a maioria dos alunos apresentou concepções espontâneas sobre conceitos e fenômenos de Óptica, indicando que ainda não tinham tido a oportunidade de estudar esta área da física. Desta forma, esta revelação reforçou o interesse no desenvolvimento da presente proposta e respectiva intervenção neste contexto particular, em uma turma de estudantes matriculados na EJA.

Reitera-se que os resultados do pré-teste serviram para justificar a escolha das atividades subsequentes. Os resultados orientaram o professor, nortearam os caminhos a seguir, identificando o ponto de partida em relação ao pensar quais conceitos básicos a serem considerados e escolha do material mais adequado. Os resultados evidenciados sobre os saberes 
prévios serviram de apoio para a aplicação de estratégias de ensino que estivessem relacionadas aos indicadores apresentados pela turma. Desta maneira, a proposta está em acordo com Vygotsky (2001), que ressalta a importância do resgate e aproveitamento do conhecimento que o aluno possui, podendo favorecer a formação de conceitos científicos.

\section{B. Aplicação da estratégia E2}

Em seguida, aplicou-se a segunda estratégia, exibindo para os alunos dois vídeos do Telecurso $2000^{8}$, "Introdução à Óptica Geométrica (Teleaula 31)" e a "História e a Evolução de conceitos sobre Óptica (Teleaula 35)". A escolha dessas duas teleaulas é justificada por elas abordarem conceitos presentes nas questões do pré-teste, apresentando demonstrações de experimentos de fenômenos ópticos, com materiais simples, e priorizarem a relação com o cotidiano, criando uma oportunidade para que o aluno possa compreender e situar melhor os conceitos que dariam suporte às discussões posteriores. Além disso, o material pode ser acessado em casa, no trabalho ou na escola; as aulas são curtas, com duração de aproximadamente 15 minutos, e têm uma revisão no final. A atividade foi realizada em duas aulas de 50 minutos para cada vídeo, sendo que no restante do tempo foi realizado um debate com os alunos sobre os temas.

No vídeo "Introdução à Óptica Geométrica” são discutidas as propriedades de reflexão, refração e emissão de luz; cores de um corpo; formação de imagens. Além disso, são apresentados os conceitos de luz, sombra e penumbra. Após a apresentação de todos os conceitos, o aluno é questionado quanto ao fato de enxergarmos. O vídeo sugere também a construção de uma câmara escura, fazendo uma analogia ao funcionamento de uma câmara fotográfica.

O segundo vídeo "História da evolução das ideias sobre o conceito de Luz" contempla os tópicos: velocidade da luz; problematização de que os conhecimentos de Ciência são mutáveis; natureza dual da luz. Após a discussão filosófica do vídeo, os alunos manifestaram interesse em compreender a evolução histórica da Física, demonstrando em vários momentos curiosidade em relação aos questionamentos e os respectivos argumentos ilustrados no vídeo.

Em seguida, foi realizado um debate no qual cada aluno deveria escolher e responder a uma pergunta do questionário pré-teste. Ao final todas as questões foram respondidas, por meio de questionamentos e discussões, até que nenhum aluno demonstrasse dúvidas sobre o tema.

Esta etapa representou um papel importante na construção da sequência, pois após assistirem as teleaulas, as observações feitas pelos alunos mostraram que estes tinham compreendido os fenômenos e conceitos apresentados, inclusive admitindo que, até aquele momento, eles desconheciam aqueles conceitos. Os alunos elogiaram as teleaulas, ressaltando

\footnotetext{
8 Disponível em: <http://www.telecurso.org.br/fisica>. Acesso em: nov. 2017.
} 
que as demonstrações exibidas no vídeo, possibilitaram aos mesmos, pela primeira vez, a visualização de experiências realizadas em um laboratório.

\section{Aplicação das estratégias E3 e E4}

A terceira etapa do trabalho baseou-se no processo de apropriação dos conceitos de Óptica, por meio da leitura de textos didáticos e artigos de divulgação científica. A escolha dos artigos estabeleceu uma relação direta com os temas escolhidos, aprofundando a discussão dos conceitos vistos nas outras etapas e contribuindo para o desenvolvimento da aprendizagem do aluno.

Assim foram selecionados alguns artigos de divulgação científica da revista "Física na Escola" e textos complementares do GREF que abordam o conteúdo de Óptica e também apresentam experimentos de demonstração para melhor compreensão dos assuntos trabalhados. Foram selecionadas as seguintes leituras:

a. Fotografando com a câmara escura de orifício (SOUZA; NEVES; MURAMATSU, 2007);

b. Eclipses solares e lunares (LIMA; VILLAS da ROCHA, 2004);

c. Os fundamentos da Luz laser (BAGNATO, 2001);

d. Textos do Caderno "Leituras de Física" (GREF, 1993, p. 45-47).

Vale ressaltar que o material adotado pela escola para ser utilizado no ensino de Física da EJA é constituído de apostilas, que apresentam apenas um resumo dos conceitos, além de priorizar exercícios de aplicação direta de fórmulas matemáticas para a sua resolução. Os alunos não tinham conhecimento da possibilidade de trabalhar um conteúdo de forma contextualizada, ou mesmo com a utilização de demonstrações dos fenômenos. Assim, estes consideraram essa estratégia inovadora, por ser a primeira vez que tiveram contato com uma linguagem que associa os conceitos de Óptica com aplicações e fenômenos do cotidiano. Este fato pode estar relacionado com a dificuldade dos alunos para explicar a formação do arcoíris.

A atividade teve a duração de duas aulas de 50 minutos. Na primeira aula, os alunos foram orientados a buscar os textos na internet, o que também proporcionou a possibilidade de encontrar outros textos sobre o assunto, além de vídeos com demonstrações. A turma foi dividida em quatro grupos de cinco alunos, e cada grupo ficou encarregado de fazer a leitura de um artigo, grifando as palavras desconhecidas e tentando compreender a ideia central dos textos. Na segunda aula, cada grupo apresentou o tema de sua leitura para toda a turma, a discussão envolveu todos os alunos que participaram questionando os colegas sobre os conceitos, detalhes dos fenômenos ou da montagem dos experimentos apresentados nos textos. $\mathrm{O}$ envolvimento dos alunos nesta atividade, trazendo outros textos sobre o assunto, foram indicadores do interesse e vontade de aprender da turma. 


\section{Aplicação das estratégias E5 e E6}

A reconstrução de experimentos, realizada na quinta estratégia, abriu um espaço prático para o aprendizado dos alunos. Foram escolhidos experimentos que ilustram os conceitos discutidos nas etapas anteriores, ou que foram citados nos textos de divulgação científica. Desta maneira, foram trabalhados os temas "Câmara escura", "Composição de outras cores", "Reservatório de água" e "Cartões com furos". A reação dos alunos surpreendeu, pois eles demonstraram muito interesse e revelaram que era a primeira oportunidade de contato com uma aula experimental.

Foram disponibilizadas três aulas de 50 minutos para a preparação e realização desta estratégia. Coube aos alunos dividir as tarefas, ficando encarregados de escolher qual seria o melhor material a ser utilizado, onde comprar, quem compraria.

A apresentação dos experimentos pelos alunos, realizada na sexta estratégia da sequência, teve a duração de uma aula de cinquenta minutos. Os alunos utilizaram os experimentos construídos para demonstrar e explicar os fenômenos físicos, relatando também as dificuldades enfrentadas na sua construção. A seguir são detalhadas a construção e apresentação de cada experimento.

\section{- Compondo outras cores (GREF, 1993)}

O grupo decidiu comprar uma caixa de madeira pronta e adaptá-la ao experimento. Durante a construção, os alunos relataram dificuldades com a adaptação da parte elétrica do experimento e para fazer uma abertura circular lateral na caixa.

Os alunos acharam surpreendente o fato de conseguirem obter a cor branca através da mistura de cores; eles também relacionaram os fenômenos de reflexão e absorção da luz na visualização das cores dos objetos, e identificaram as diferenças existentes entre os processos de mistura de luzes e pigmentos coloridos. Neste contexto, foi discutida a formação do arcoíris e a dispersão das cores.

Foi possível perceber um entrosamento muito bom entre os integrantes do grupo, que além de discutirem os conceitos de acordo com a física escolar, explicando os fenômenos relacionados, demonstraram ter aproveitado o ambiente de aprendizagem proporcionado pela construção do experimento.

\section{- Câmara escura (SOUZA; NEVES; MURAMATSU, 2007)}

O segundo grupo construiu uma câmara escura, usando uma caixa de madeira pintada com tinta preta por dentro e por fora, um acabamento interessante. Os alunos conseguiram demonstrar o fenômeno físico estabelecido pelo experimento de forma bem nítida, adaptando a sala de aula com cortinas de TNT preto, buscando um ambiente escuro apropriado à apresentação. Os alunos explicaram porque a imagem projetada estava invertida através da propagação retilínea da luz, enfatizando que essa era uma das propriedades da luz, sobre as quais 
eles tinham sido questionados no início do estudo. Tendo em mente as necessidades de aprendizagem indicadas no pré-teste, a construção desse experimento contribuiu para a reelaboração de conceitos sobre imagens, visão e propriedades da luz.

- Reservatório de água (MAGO DA FÍSICA, 2009)

Para o experimento do terceiro grupo, construção do reservatório de água, os alunos compraram um laser verde e placas de vidro com as dimensões sugeridas, e as colaram com silicone formando o reservatório.

Esse experimento contribuiu para que o aluno visualizasse, através da demonstração, a propagação da luz em meios homogêneos e transparentes e em meios heterogêneos com densidades diferentes. $\mathrm{O}$ interessante desse experimento é que, apesar da simplicidade, ele permitiu aos alunos observarem fenômenos como reflexão, refração e reflexão total da luz. No dia da apresentação, para conseguir um meio que apresentasse diferentes densidades, o grupo pesquisou e levou uma mistura de água com açúcar preparada no dia anterior.

- Cartões com furos (LAVARDA, 1997)

O quarto grupo construiu o experimento "Cartões com furos", obedecendo às dimensões sugeridas no roteiro e reproduzindo o mesmo com facilidade. Os alunos cumpriram as metas estabelecidas para a demonstração desse experimento, explicando como seria possível enxergar nitidamente um texto que se encontra muito próximo dos olhos, por meio da difração da luz.

Ao final de todas as demonstrações, ficou claro que o mais importante foi a percepção dos alunos de que na verdade o trabalho era um só, todos contribuíram por meio dos experimentos para construir um entendimento mais amplo sobre os conceitos da Óptica.

Além de observar que os alunos haviam conseguido alcançar o objetivo central dessa atividade, ou seja, relacionar os conceitos e interpretar os fenômenos, chamou a atenção o compromisso e a responsabilidade que os grupos assumiram ao apresentar o experimento, tendo que improvisar em alguns momentos. A necessidade de fazer uma intervenção no espaço da sala de aula foi muito importante para a formação dos alunos, favorecendo a tomada de decisões.

\section{E. Aplicação da estratégia E7}

$\mathrm{Na}$ estratégia E7 foi aplicado aos 20 alunos participantes o mesmo questionário do pré-teste, referido agora como pós-teste. Esta etapa teve a duração de uma aula de 50 minutos. A seguir é apresentada a análise das respostas dos alunos ao pós-teste.

Na primeira questão, as respostas dos alunos sobre o conceito de luz foram classificadas em quatro temas-chave deste assunto da Física: Onda eletromagnética, Radiação eletromagnética, Energia e Cores. Onze alunos afirmaram que luz é uma onda eletromagnética, 
definindo o tema Onda eletromagnética, como nas respostas de:

Aluno $\mathrm{A}_{12}$ : "É uma onda eletromagnética. Possui uma característica dual, pode se comportar tanto como uma onda quanto como uma partícula";

Aluno $\mathrm{A}_{20}$ : "São ondas eletromagnéticas que sensibilizam nossos órgãos visuais";

Aluno $\mathrm{A}_{2}$ : "É a propagação de ondas eletromagnéticas".

Nessa mesma linha, quatro alunos associaram luz com Radiação eletromagnética, afirmando que:

Aluno $\mathrm{A}_{19}$ : "Luz é uma radiação eletromagnética";

Aluno $\mathrm{A}_{8}$ : "Luz é uma radiação eletromagnética que sensibiliza nossos órgãos visuais".

A definição do tema Energia, formado pelas respostas de três alunos, baseou-se em respostas do tipo:

Aluno $\mathrm{A}_{11}$ : "É um feixe de energia independente que se propaga em linha reta";

Aluno $\mathrm{A}_{17}$ : "É um tipo de energia que emite reflexão".

E duas respostas que se enquadraram no tema Cores foram:

Aluno $\mathrm{A}_{13}$ : "É uma reação eletromagnética formando todas as cores";

Aluno $\mathrm{A}_{15}$ : "É um encontro de todas as cores".

Os dois primeiros temas foram o que mais se destacaram porque a maioria dos alunos passou a identificar luz como uma onda ou radiação eletromagnética, em acordo com a física escolar, o que foi interpretado como um resultado satisfatório. $\mathrm{O}$ restante associou luz com energia e cores, respondendo parcialmente à questão, pois alguns citaram propriedades que não se aplicam em todas as situações, como a propagação em linha reta, encontro de todas as cores, ou associações mal definidas como em "energia que emite reflexão". Percebe-se a evolução conceitual dos alunos $\mathrm{A}_{2}$ e $\mathrm{A}_{20}$, cujas respostas no pré-teste foram classificadas como Associações isoladas, e após a intervenção, passaram a associar luz com onda ou radiação eletromagnética. Por outro lado, tem-se casos como o aluno $\mathrm{A}_{17}$ que continuou a associar luz com energia. De um modo geral, nota-se que a maioria dos alunos conseguiu agregar conceitos, aplicando-os na tentativa de responder à questão na sua própria linguagem, explicando com suas palavras as questões, o que indica um início de apropriação do conhecimento.

$\mathrm{Na}$ análise da segunda questão, sobre o que são ondas eletromagnéticas, foram identificadas, a partir da análise das respostas dadas, duas categorias Propriedades e Tecnologia. $\mathrm{Na}$ categoria Propriedades foram enquadradas as respostas de 18 alunos que apresentaram propriedades inerentes às ondas divididas em: Variação do Campo Elétrico/Magnético, por dez alunos:

Aluno A8/ $\mathrm{A}_{9}:$ "Ondas eletromagnéticas é a variação do campo elétrico"; 
Aluno $\mathrm{A}_{2} / \mathrm{A}_{18}$ : "É uma variação do campo eletromagnético";

Propagação, por seis alunos:

Aluno $\mathrm{A}_{20} / \mathrm{A}_{15}$ : "São ondas que se propagam sem a necessidade de um meio";

Aluno $\mathrm{A}_{14}$ : "São ondas que se propagam em todas as direções";

Aluno $\mathrm{A}_{11}$ : "São ondas de energia que se propagam em linha reta";

e Característica dual, por dois alunos:

Aluno $\mathrm{A}_{12} / \mathrm{A}_{6}:$ "Possui uma característica dual, pode se comportar tanto como uma onda quanto como partícula".

Na categoria Tecnologia, têm-se as respostas de dois alunos:

Aluno A : "São ondas que encontramos através do funcionamento dos aparelhos de microondas, celular e energia solar".

Aluno $\mathrm{A}_{17}$ : "São ondas responsáveis pelo funcionamento da tecnologia".

Observa-se que metade dos alunos relacionou o conceito de ondas eletromagnéticas com a variação do campo elétrico, do campo magnético, ou de ambos. A maioria não explicou como ocorre essa variação, mas sabe que a mesma está diretamente relacionada com as ondas eletromagnéticas. Além disso, dois alunos apresentaram respostas que relacionavam as ondas eletromagnéticas com sua aplicação tecnológica. Embora as respostas dos estudantes tenham se distanciado dos conhecimentos curriculares da física escolar em alguns aspectos da óptica, observa-se que todos eles buscaram imprimir suas compreensões e entendimentos sobre esse tema, principalmente, citando características das ondas eletromagnéticas. Isto pode ser visto no caso dos alunos $\mathrm{A}_{18}$ e $\mathrm{A}_{15}$, cujas respostas a esta questão no pré-teste indicaram uma associação simples de palavras (magnetismo; magnésio), e no pós-teste, $\mathrm{A}_{18}$ foi capaz de definir e $\mathrm{A}_{15}$ citar uma propriedade das ondas eletromagnéticas. $\mathrm{O}$ aluno $\mathrm{A}_{7}$, que inicialmente definiu ondas eletromagnéticas como energia presente "em todos os lugares da cidade", passou a descrevê-las como ondas que contribuem para o funcionamento de vários aparelhos.

A análise das respostas da terceira questão ('Porque enxergamos objetos que não emitem luz'?) apresentou quatro temas de estudos: Reflexão; Radiação/ iluminação do objeto; Sensibilidade nos olhos e Cores. As respostas de dez alunos definiram o tema Reflexão, como pode ser visto nos exemplos a seguir:

Aluno $\mathrm{A}_{11}$ : "A luz branca ou parte dela é refletida pelo objeto, tornando-o visível";

Aluno A 6 : "Enxergamos a reflexão emitida pelo objeto de forma difusa";

Aluno $\mathrm{A}_{17}$ : "Mesmo não emitindo luz eles refletem, permitindo que sejam enxergados".

As respostas de seis alunos foram classificadas no tema Radiação/iluminação do objeto, mostradas nas falas abaixo: 
Aluno $\mathrm{A}_{5}$ : "Por causa da radiação emitida pela luminosidade em volta do objeto";

Aluno A9: "Pela radiação feita pela luz ao redor do objeto".

Três alunos associaram o fato de enxergarmos os objetos à Sensibilidade nos olhos, como pode ser visto nas respostas abaixo:

Aluno $\mathrm{A}_{13}$ : "Porque com a luz enxergamos e temos sensibilidades, e sem a luz, os raios não são refletidos e assim, não conseguimos enxergar certos objetos";

Aluno $\mathrm{A}_{19}$ : "Porque com a luz temos a sensibilidade dos nossos olhos e sem a luz nossos órgãos visuais não sensibilizam”.

Apenas um aluno utilizou a ideia das cores que compõem um raio de luz branca, explicando o processo por meio da absorção e reflexão da luz pelos objetos, como pode ser conferido abaixo:

Aluno $\mathrm{A}_{3}$ : "Porque os corpos refletem, absorvem algumas cores e refletem as que não são absorvidas".

Assim, constatou-se que metade dos alunos relacionou o fenômeno referido à reflexão, como no exemplo em que foi mencionada a reflexão difusa da luz. A outra metade mencionou a iluminação dos objetos por uma fonte externa, sem mencionar a reflexão da luz; e alguns citaram a sensibilidade nos olhos provocada pela presença da luz. Nesta questão, notase a evolução dos alunos $\mathrm{A}_{3}$ e $\mathrm{A}_{15}$, que no pré-teste associaram o tamanho do objeto com a nossa capacidade de vê-los, e no pós-teste responderam que este fenômeno se deve à reflexão da luz pelos objetos. Em particular, a resposta do aluno $\mathrm{A}_{3}$ é bem completa. Vale notar também o progresso dos alunos $\mathrm{A}_{11}$ e $\mathrm{A}_{17}$, cujas respostas do pós-teste foram mais elaboradas em relação às respostas anteriores, ao explicar detalhes do fenômeno. Esse é um aspecto considerável no processo de aprendizagem, pois percebe-se que os alunos foram ampliando o seu vocabulário. Além disso, conseguiram associar os termos conforme uma aproximação com a linguagem científica da física escolar, demonstrando uma certa aprendizagem sobre o fenômeno estudado.

Em relação à quarta questão ('Porque nos vemos num espelho'?) evidenciou-se que todas as respostas analisadas foram associadas de alguma maneira a palavra reflexão. Para facilitar a leitura, as respostas foram separadas em duas definições relacionadas à reflexão: reflexão/ imagem (18 alunos), como em:

Aluno $\mathrm{A}_{6}$ : "Porque o encontro desses raios de luz, que são refletidos, forma a imagem";

Aluno $\mathrm{A}_{7}$ : "Porque a imagem é refletida";

e respostas que citaram apenas a reflexão da luz (dois alunos):

Aluno $\mathrm{A}_{11}$ : "Pois sua superficie reflete os raios de luz que incidem no mesmo"; Aluno $\mathrm{A}_{12}$ : "Por causa da reflexão dos raios". 
A análise das respostas dessa questão foi bastante satisfatória, pois, todos os alunos relacionaram o fenômeno com a reflexão, mesmo reconhecendo que algumas respostas tenham sido vagas. Alguns aprofundaram-se um pouco mais, pois utilizaram na explicação conceitos que discutiam a formação de imagens, a propagação da luz e incidência de raios de luz.

Analisando a quinta questão ('Como é formado o arco-íris'?), as respostas foram identificadas em relação a dois conceitos principais: Cores, com respostas de onze alunos que se referem à decomposição ou junção das cores:

Aluno $\mathrm{A}_{10}$ : "É formado pela junção das cores primárias";

Aluno $\mathrm{A}_{6}$ : "A luz branca emitida pelo Sol se decompõe em sete cores”;

e Reflexão da luz na água, em que nove alunos deram respostas do tipo:

Aluno $\mathrm{A}_{14}$ : "A luz incidente do Sol é desviada por uma gotícula de água que difrata em vários comprimentos de onda”;

Aluno $\mathrm{A}_{15}$ : "É feito pela luz do Sol que se reflete na água da chuva".

A resposta do aluno $\mathrm{A}_{14}$ descreve bem o fenômeno, embora tenha demonstrado que não se apropriou do conceito de difração, ou simplesmente confundiu o termo com refração. Percebe-se que as palavras reflexão e refração foram relacionadas em várias respostas. A resposta do aluno $\mathrm{A}_{15}$, antes e após a intervenção, mostra que este entendeu a diferença entre raio de luz e cores, evitando esta terminologia no pós-teste. $\mathrm{O}$ aluno $\mathrm{A}_{10}$, que antes apenas relatou que são necessários sol e chuva para a formação do arco-íris, no pós-teste, mostrou um entendimento parcial do processo. Neste contexto, acredita-se que esses fatos são indicadores de que os alunos se encontram em um processo de aprendizagem, relacionando os conceitos aos fenômenos presentes no cotidiano.

Para as respostas à sexta questão sobre as propriedades da luz, foram definidos seis temas, com suas respectivas frequências entre parênteses: Independência dos raios (14); Propagação retilínea (10); Velocidade da luz (4); Refração e reflexão da luz (2); Energia (2); Não sei (2). Algumas respostas se encaixam em mais de um tema, como por exemplo, os alu$\operatorname{nos} \mathrm{A}_{3}, \mathrm{~A}_{4}, \mathrm{~A}_{5}, \mathrm{~A}_{6}, \mathrm{e} \mathrm{A}_{8}$ que indicam em suas respostas duas ou mais propriedades da luz:

Aluno $\mathrm{A}_{3}$ : "Velocidade, propagação retilínea da luz ou independência dos raios luminosos";

Aluno A4: "Velocidade ou propagação da luz";

Alunos $\mathrm{A}_{5} / \mathrm{A}_{6} / \mathrm{A}_{8}$ : "Propagação da luz, propagação retilínea, interdependência dos raios";

Aluno $\mathrm{A}_{17}$ : “A luz apresenta as propriedades de refração e reflexão de imagens”.

Assim, observa-se que a propriedade da luz mais citada foi a independência dos raios luminosos, seguida pela propagação retilínea da luz. Em outras respostas, dois alunos citaram que a luz é uma fonte de energia, como na resposta: 
Aluno $\mathrm{A}_{16}$ : "Fonte de energia que ilumina nossas vidas";

e um relacionou com a formação de imagens (Ver resposta do aluno $A_{17}$ ). Apenas dois alunos disseram que não sabiam responder à questão.

Dentre os que citaram alguma propriedade da luz, sete alunos apresentaram nas suas respostas as explicações das propriedades, tais como:

Aluno A $\mathrm{A}_{12}$ : "Propagação retilínea. A luz se propaga em linha reta quando atravessa um meio homogêneo e transparente";

ou a resposta que diz:

Aluno $\mathrm{A}_{7}$ : "Raios independentes. Dois raios depois que se cruzam continua no mesmo caminho sem sofrer desvios".

Este fato mostra que os alunos, em geral, justificaram de forma objetiva suas respostas.

\section{Discussão da aplicação das estratégias}

A fase inicial do trabalho consistiu na aplicação do pré-teste (E1). A análise dos dados coletados assumiu um papel importante para o professor, pois permitiu a identificação dos conhecimentos prévios dos alunos.

$\mathrm{Na}$ perspectiva de desenvolver um ensino de física contextualizado ${ }^{9}$, os conhecimentos prévios dos alunos foram aproveitados na discussão de conceitos científicos relacionados à Óptica. De acordo com os PCN (2000, p.78),

O tratamento contextualizado do conhecimento é o recurso que a escola tem para retirar o aluno da condição de espectador passivo. Se bem trabalhado permite que, ao longo da transposição didática, o conteúdo do ensino provoque aprendizagens significativas que mobilizem o aluno e estabeleçam entre ele e o objeto do conhecimento uma relação de reciprocidade. A contextualização evoca por isso áreas, âmbitos ou dimensões presentes na vida pessoal, social e cultural, e mobiliza competências cognitivas já adquiridas.

Por meio da contextualização facilita-se a compreensão desses conceitos permitindo que o aluno perceba a relação existente entre o que ele aprende na escola e o seu cotidiano. Assim, as demais estratégias que compõem a sequência de atividades foram definidas tendo como base as necessidades dos alunos, identificadas na primeira estratégia.

\footnotetext{
${ }^{9}$ Propõe-se um ensino de física contextualizado em acordo com os PCN (BRASIL, 2000, p.78) que diz "Contextualizar o conteúdo que se quer aprendido significa, em primeiro lugar, assumir que todo conhecimento envolve uma relação entre sujeito e objeto".
} 
As teleaulas, exibidas na segunda estratégia, auxiliaram a discussão de conceitos básicos da Óptica, necessidade detectada por meio do pré-teste, permitindo uma melhor compreensão dos conceitos que serviram de suporte às discussões posteriores.

O uso de textos e artigos de divulgação científica (estratégia E3) também foi uma etapa importante, que propiciou uma sequência ao processo de apropriação dos conceitos de Óptica. Além disso, em alguns casos, essa estratégia foi considerada inédita por alguns alunos, pois muitos nunca tinham tido contato com textos e artigos de divulgação científica. Na sequência foi realizado um debate com os alunos (estratégia E4), aproveitando o momento criado pela etapa anterior, retomando a discussão dos conceitos e relacionando-os às aplicações do cotidiano. O período de aplicação da E4 foi um campo de observação muito rico, em que o professor pode se colocar na condição de observador e identificar a concepção de cada aluno sobre os conceitos vistos, e até mesmo perceber se esse aluno conseguiu se posicionar de forma crítica sobre o que está sendo discutido. Para Vygotsky (2001), o processo de aprendizagem deve sofrer a intervenção do professor, que deve mediar o conhecimento entre seus alunos.

A montagem de experimentos, feita pelos alunos na estratégia E5, abriu um espaço para a construção de conceitos pelos alunos. À medida que se envolveram nas atividades, os alunos perceberam que na realidade esse foi um espaço não apenas de "construção" de experimentos, mas de "reconstrução" de conceitos, pois foi nesse momento que se fez uma análise crítica da situação, pesquisando por maneiras alternativas para montar o equipamento. Assim, essa etapa foi muito importante pelo fato da reconstrução permitir ao aluno rever o seu aprendizado, compreender o que "deu errado" e porque isso ocorreu. Segundo Vygotsky (2001) a reelaboração de conceitos é uma fase fundamental no processo de aprendizagem, pois o aluno tem a oportunidade de vivenciá-los, no caso durante a reconstrução dos experimentos e por meio da intervenção do professor.

A apresentação dos experimentos pelos alunos (estratégia E6) foi uma etapa essencial para o processo de aprendizado proposto, pois disponibilizou ao professor outro espaço para observar o desenvolvimento dos alunos. Neste momento, foram trabalhadas com os alunos formas de comunicação. Além disso, houve a troca de informações e experiências na qual cada grupo teve a oportunidade de conhecer os trabalhos dos outros e aprender com seus colegas. Os trabalhos desenvolvidos em grupo apresentaram vários fatores favoráveis ao processo de aprendizagem, dentre eles, pode-se citar a possibilidade de os alunos com um nível de desenvolvimento mais elevado contribuir para atuar na zona de desenvolvimento proximal dos colegas, favorecendo assim, a aprendizagem e o desenvolvimento intelectual da turma.

$\mathrm{Na}$ aplicação do pós-teste (estratégia E7), o professor pode acompanhar o progresso de cada aluno separadamente. As atividades foram aplicadas no contexto das aulas, assim a participação dos alunos na sequência didática não teve como finalidade a atribuição de pontos. Entretanto, durante o processo foi possível perceber várias oportunidades para a realiza- 
ção de avaliações formativas ${ }^{10}$, principalmente nos debates e apresentações de trabalhos, que são momentos caracterizados pela exposição de conceitos e explicação de fenômenos pelos alunos. Dessa maneira, pode-se afirmar a partir de dados observacionais, que os alunos passaram, ao longo do processo, a ter mais facilidade para falar em público, expor suas opiniões e dúvidas. Neste contexto avaliativo, a análise dos dados do questionário pós-teste indica que houve o desenvolvimento da aprendizagem de conceitos de Óptica, como será discutido na seção seguinte.

Após a aplicação de todas as atividades, o momento também permitiu ao professor fazer uma autocrítica, detectando o que foi viável durante esse processo de aprendizado, e indicar sugestões de mudanças para uma aplicação posterior, como aumentar o número de textos utilizados, incentivar a busca por outros textos, e trabalhar com grupos menores, garantindo maior participação dos alunos nas exposições.

\section{Discussão dos resultados}

Uma comparação dos resultados dos questionários aplicados permite revelar, mesmo de forma aproximada, que os alunos se apropriaram de alguns conceitos da Óptica a partir da intervenção proposta. Percebe-se, em nossa opinião, que os alunos compreenderam aspectos deste tema da física escolar. A partir das atividades e discussões geradas os estudantes confrontaram os conceitos científicos com suas concepções espontâneas no campo da Óptica. Desta forma, acredita-se que os mesmos tiveram a oportunidade de enriquecer seus conhecimentos prévios. Um indicador deste fato está no índice de respostas da categoria "Não sei", que caiu para zero no questionário pós-teste, com exceção da última pergunta na qual dois alunos, mesmo após realizar todas as atividades, disseram não saber indicar nenhuma propriedade da luz.

Assim, destaca-se a importância em mapear os conceitos espontâneos dos alunos sobre o assunto a ser abordado, para, a partir destes dados, planejar as atividades da sequência. Vale ressaltar que não foi uma prioridade classificar as respostas dadas pelos alunos como certas ou erradas, ao contrário disso, considerou-se a classificação conceitual de suas respostas, conforme a ideia central correspondente, em uma tentativa de acompanhar a evolução dos alunos.

Antes de participar da sequência didática, poucos alunos associaram o fato de enxergarmos os objetos sem luz própria ao fenômeno da reflexão, e ainda, quatro alunos associaram esta propriedade ao tamanho do objeto. No resultado do pós-teste observa-se que os alunos mostraram compreender melhor o fenômeno, citando, além da reflexão da luz, a presença de iluminação externa e a sensibilidade dos olhos.

\footnotetext{
10 De acordo com Perrenoud (1998), uma avaliação formativa constitui um processo contínuo que permite o professor observar sistematicamente os alunos em atividades variadas contribuindo para o desenvolvimento do processo de aprendizagem por meio das intervenções propostas.
} 
É interessante observar, em várias situações no pré-teste, a utilização da palavra "cores" para se referir ao raio de luz, ou à luz se propagando em um meio. Embora no feixe de luz branca haja a presença de vários comprimentos de onda (ou frequências), em geral, não é comum se referir a um raio de luz como cor. No pós-teste, após assistir aos vídeos, ler artigos e discutir os conceitos, percebe-se que nenhum aluno continuou usando esta terminologia no sentido de raio de luz, mas sim, para identificar as cores que compõem a luz branca.

Em relação ao desenvolvimento do aprendizado, pode-se apontar a trajetória do aluno $\mathrm{A}_{4}$, que respondeu "não sei” para todas as questões do pré-teste. Já no pós-teste, o resultado foi bem diferente, pois ele foi capaz de definir luz "como ondas eletromagnéticas"; explicou que "Onda eletromagnética é a variação do campo elétrico"; que é possível enxergar um objeto que não emite luz "Devido à radiação feita por conta da luz ao redor do objeto"; que nos vemos em um espelho "Porque o raio de luz é refletido (ondas eletromagnéticas)"; que o arco-íris "É formado quando ocorre o reflexo das cores nas gotas de chuva"; e citou três propriedades da luz, "Velocidade ou propagação da luz; Independência dos raios luminosos". Embora nem todas as respostas estejam completamente em acordo com a física escolar, é visível o ganho conceitual deste aluno.

Outro fator que chamou atenção foi a forma com que os alunos utilizaram os termos câmara escura e formação de imagens, mencionando-os de forma desconexa e vaga no préteste. Ao contrário disso, percebe-se pelas respostas do pós-teste, que os alunos conseguiram relacionar estes termos aos fenômenos. No caso da câmara escura, destaca-se a leitura do artigo "Fotografando com a câmara escura de orificio" (SOUZA; NEVES; MURAMATSU, 2007) sugerida na terceira estratégia, a qual foi essencial no auxílio da compreensão dos conceitos relacionados a esse equipamento. Com relação à formação de imagem, o assunto não foi tratado diretamente em uma estratégia, mas é importante ressaltar que foram apresentadas em vários momentos explicações relacionadas a esse fenômeno.

No pós-teste, de uma maneira geral, as respostas apresentaram conceitos científicos relacionados à questão respondida, sendo que em alguns casos, os alunos indicaram aplicações tecnológicas ou características do conceito discutido. Percebe-se, assim, que as atividades propiciaram um enriquecimento do vocabulário envolvido na discussão, esclarecendo conceitos e relacionando-os às aplicações do cotidiano.

\section{Considerações finais}

Neste trabalho foi relatada a aplicação de uma sequência didática para ensinar Óptica a alunos da Educação de Jovens e Adultos (EJA). A sequência de atividades é composta por estratégias como exibição de vídeos, leitura de artigos de divulgação científica, reconstrução e demonstração de experimentos, e discussões em grupo, em acordo com os métodos aplicados nos trabalhos de Costa (2008), Ferreira (2005) e Espíndola (2006). 
Todas as atividades foram trabalhadas sob o enfoque de um ensino contextualizado, desenvolvendo habilidades favoráveis ao processo de aprendizagem dos alunos, priorizando a autonomia intelectual e o pensamento crítico. Nesta perspectiva, este trabalho está em acordo com a proposta de ensino apresentada pelo ENCCEJA, que valoriza cada etapa no processo de aprendizagem, e destaca a importância e a necessidade da contextualização dos conceitos (BRASIL, 2003).

Enfatiza-se que para desenvolver um ensino contextualizado é essencial o papel do professor, que durante as práticas educativas deverá sempre estar relacionando os conceitos discutidos em sala de aula com o cotidiano dos alunos. Nesta expectativa, a utilização das estratégias de ensino apresentadas, quando bem conduzidas pelo professor, pode propiciar um aprendizado eficaz e de qualidade para os alunos da EJA, permitindo a eles a aplicação desse aprendizado em sua vida.

Neste sentido, em acordo com Vygotsky busca-se um ensino baseado na compreensão de conceitos, fundamental na formação intelectual dos alunos. Segundo Vygotsky (2001, p.247), “[...] o ensino direto de conceitos sempre se mostra impossível e pedagogicamente estéril. O professor que envereda por esse caminho costuma conseguir senão uma assimilação vazia de palavras pura e simples." Para evitar isso, as estratégias utilizadas foram selecionadas seguindo critérios estabelecidos pelas necessidades apresentadas pelos alunos, sendo que cada estratégia corresponde a uma etapa no processo de aprendizagem em acordo com o referencial teórico utilizado. Assim, na sequência foram identificados os conceitos espontâneos dos alunos; realizadas discussões para uma apresentação inicial dos conceitos científicos; atividades de leitura e debates que propiciaram a apropriação destes conceitos; e finalmente a reelaboração destes conceitos por meio da reconstrução e apresentação de experimentos.

Ressalta-se que foi possível observar durante o percurso, o desenvolvimento conceitual dos alunos que participaram deste trabalho, respeitando as suas limitações e identificando o nível de dificuldade de cada um. Desta maneira, pode-se considerar que este trabalho produziu um resultado positivo, ampliando o nível de conhecimento dos alunos envolvidos.

\section{Referências}

BAGNATO, V. S. Os fundamentos da Luz laser. Física na Escola, v. 2, n. 2, 2001.

BRASIL. Ministério da Educação, Secretaria de Educação Média e Tecnológica. Parâmetros Curriculares Nacionais: Ensino Médio. Brasília: Ministério da Educação, 2000.

BRASIL, Secretaria de Educação Média e Tecnológica. PCN+ Ensino Médio: orientações educacionais complementares aos Parâmetros Curriculares Nacionais. Ciências da Natureza, Matemática e suas Tecnologias. Brasília: Ministério da Educação, 2002.

BRASIL. Lei no 9.394, de 20 de dezembro de 1996. Estabelece as Diretrizes e Bases da Educação Nacional. Brasília: Casa Civil, 1996. Diário Oficial da União, Brasília, 23 dez. 1996. 
BRASIL. Instituto Nacional de Estudos e Pesquisas Educacionais Anísio Teixeira (Inep). Livro introdutório: documento básico, ensino fundamental e médio. Brasília, 2002.

BRASIL. Instituto Nacional de Estudos e Pesquisas Educacionais Anísio Teixeira (Inep). Ciências da Natureza e suas Tecnologias: livro do estudante: ensino médio. Brasília, 2006.

BRESOLIN, K. R. Projetos Temáticos: Ensino de Física na Educação de Jovens e Adultos (EJA). 2014. 115f. Trabalho de Conclusão de Curso (Licenciatura em Física) Universidade Federal de Santa Catarina, Florianópolis.

COSTA, F. V. A eletricidade na EJA do ensino médio: uma proposta. 2008. 146 f. Dissertação (Mestrado em Ensino de Ciências e Matemática) - Instituto de Ciências Humanas, Pontifícia Universidade Católica de Minas Gerais, Belo Horizonte.

CUNHA, E. L.; DICKMAN, A. G. Ensinando óptica a jovens e adultos: elaboração de uma sequência didática. In: ENCONTRO DE PESQUISA EM ENSINO DE FÍSICA, 14, 2012, Maresias (SP). Anais... São Paulo: Sociedade Brasileira de Física, 2012.

CUNHA, E. L. Ensino de física na educação de jovens e adultos: elaboração de uma sequência didática para o ensino de óptica. 2011. 279 f. Dissertação (Mestrado em Ensino de Ciências e Matemática) - Instituto de Ciências Humanas, Pontifícia Universidade Católica de Minas Gerais, Belo Horizonte.

ESPÍNDOLA, K. A estratégia dos projetos didáticos no ensino de física na educação de jovens e adultos (EJA). 2006. 62f. Dissertação (Mestrado Profissional em Ensino de Física) - Instituto de Física, Universidade Federal do Rio Grande do Sul, Porto Alegre .

FERREIRA, A. Ensino de Física das Radiações na Modalidade EJA: uma proposta. 2005. 167f. Dissertação (Mestrado em Ciências/Física) - Instituto de Física, Faculdade de Educação, Universidade de São Paulo, São Paulo.

GREF: GRUPO DE REELABORAÇÃO DO ENSINO DE FÍSICA. Leituras em Física: Física 2: física térmica e óptica. São Paulo: EDUSP, 1993. Disponível em: <http://www.if.usp.br/gref/optica/optica2.pdf>. Acesso em: 20 abr. 2010.

HEWITT, P. G. Física conceitual. 9. ed. Porto Alegre: Bookman, 2002.

KRUMMENAUER, W. L; COSTA, S. S. C; SILVEIRA, F. L. S. Uma experiência de Ensino de Física contextualizada para a educação de jovens e adultos. Revista Ensaio, v. 12, n. 2, 2010. p. 69-82.

LAVARDA, F.C. Buraquinho. UNESP - Experimentos de Física para o ensino médio e fundamental com materiais do dia-a-dia. Disponível em:

<http://www2.fc.unesp.br/experimentosdefisica/opt13.htm>. Acesso em: 15 nov. 2017. 
LIMA, F. P.; VILLAS da ROCHA, J. F. Eclipses solares e lunares. Física na escola, v. 5, n. $1,2004$.

MAGO DA FÍSICA. A curva da Luz (Efeito Miragem). Youtube. 9 abr. 2017. Disponível em: <https://www.youtube.com/watch?v=UmHa-RbofVM>. Acesso em: 15 nov. 2017.

MELLO, A. C. et al. Reflexões iniciais sobre experimentação na educação de Jovens e Adultos. In: ENCONTRO DE PESQUISA EM ENSINO DE FÍSICA, 13, 2011, Foz do Iguaçu, PR. Anais... São Paulo: Sociedade Brasileira de Física, 2011.

MORAES; GALIAZZI, M. C. Análise textual discursiva. Ijuí: Unijuí, 2007.

OLIVEIRA, M. K. Vygotsky: aprendizado e desenvolvimento: um processo sóciohistórico. São Paulo: Scipione Ltda, 1997.

PERRENOUD, P. Avaliação: da excelência à regularização das aprendizagens: entre duas lógicas. Porto Alegre: Artmed, 1998.

PIETROCOLA, M. Ensino de Física: conteúdo, metodologia e epistemologia em uma concepção integradora. 2 ed. Florianópolis: UFSC, 2005.

SOUZA, C. E. R.; NEVES, J. R.; MURAMATSU, M. Fotografando com a câmara escura de orifício. Física na escola, v. 8, n. 2, 2007.

VYGotsky, L. S. A Construção do Pensamento e da Linguagem. São Paulo: Martins Fontes, 2001.

VYGOTSKII, L. S. Aprendizagem e desenvolvimento intelectual na idade escolar. In: VYGOTSKII; LURIA, A. R.; LEONTIEV, A. N. Linguagem, Desenvolvimento e Aprendizagem. Tradução: Maria da Pena Villalobos. 11 ed. São Paulo: Ícone, 2010.

VYGOTSKI, L. S. A formação social da mente. 4 ed. São Paulo: Martins Fontes, 1984. 